二次流を考慮した中規模河床形態の領域区分に関する理論的研究

\title{
Theoritical Study on Regime Criteria for River Morphology Using Three-dimensional Shear Flow Model
}

$\begin{array}{lcr}\text { 北海道大学工学部 } & \bigcirc \text { 黒木 } & \text { 幹男 } \\ \text { 北海道大学工学部 } & \text { 岸 } & \text { 力 }\end{array}$

\section{1.はじめに}

中規模河床形態の形成機構・領域区分に関してこれまでにも多くの理論的検討が行なわれてきたが，多く は掃流砂を対象にしており浮遊砂の効果に言及しているものは極めて限られている。小規模河床形態を対象 にした解析では，浮遊砂の効果について詳細な理論的検討が行なわれており，特に upper regimeにおいて は浮遊砂が河床波の形成機構に主要な役割を果していることが指摘されている。中規模河床形態の場合にも、 実河川のような掃流力が比較的大きく流砂の相当部分が浮遊形式で流送される場では，その効果を評価する ことが必要である。

従来, 中規模河床形態の解析には流れを二次元浅水流モデルを用いて表現することが多く行なわれてきた。 しかし，理論解析の中に浮遊砂を見通しの良い形ちで取り入れるためには，水深方向の分布も考慮して流れ を 3 次元的に取り扱うことが必要になる。本研究では, 直線水路の中規模河床形態上の流れの構造を解析す るとともに，浮遊砂を考慮した河床安定解析を行ない、領域区分に及ぼす影響を評価した。

\section{2. 流九の基礎方程式}

直線・矩形断面水路を考え，座標系を図一 1 のようにとる。 流れは準定常とすると，運動方程式および連続式は式(1)および 式(2)のようになる。

$$
\begin{aligned}
& v_{j} \frac{\partial v_{i}}{\partial x_{j}}=F_{i}-\frac{\partial}{\partial x_{i}}\left(\frac{p}{\rho}\right)+\frac{\partial}{\partial x_{j}}\left(\frac{\tau_{j i}}{\rho}\right) \\
& \frac{\partial v_{i}}{\partial x_{i}}=0
\end{aligned}
$$

ここに、 $v_{i}$ は流速、 $\mathrm{p}$ は圧力、Fi は外力、 $\tau_{i J}$ は乱流剪断力 であり、渦動粘性係数 （= const とする）を用いて式(3)のよ うに表わす。

$$
\frac{\tau_{j i}}{\rho}=\varepsilon\left(\frac{\partial v_{i}}{\partial x_{j}}+\frac{\partial v_{j}}{\partial x_{i}}\right)
$$

ただし、以後の解析では水面と並行な平面に作用する剪断力成
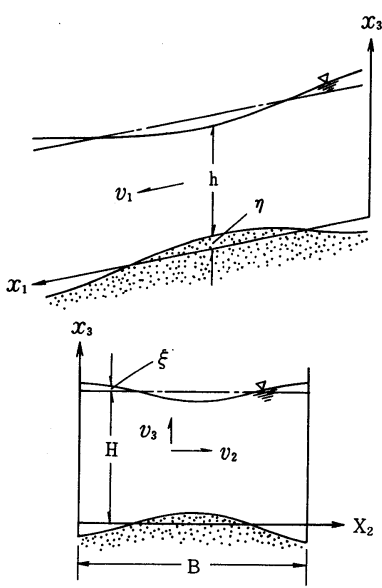

㘡-1 座標系 分のみを考え，さらに対象とする河床波の波長が水深にくらべて十分に長いことから，式(3)の右辺の表現の 中の $x_{1} \cdot x_{2}$ 方向の微分を無視する。この近似は Engelund $\cdot$ Skovgaard ${ }^{1)}$ が最初に提案した。

次に、各変量を基本流（平坦床上の二次元等流）に対応する平均量と、河床の変位に誘起される変動量と に分けて次式のように表わす。

$$
v_{i}=V_{i}+\tilde{v}_{i} \quad \text { および } \mathrm{p}=\mathrm{P}+\tilde{\mathrm{p}}
$$

ここで, 基本流の流速は, $\mathrm{V}_{1}=\mathrm{V}_{1}\left(\mathrm{x}_{3}\right), \mathrm{V}_{2}=\mathrm{V}_{3}=0$ とする。これらの関係を式(1)、(2)に代入すると, 基 本流の運動方程式は式(5)、(6)のように表わされる。また、変動量に関する運動方程式および連続式は, 変動 量の二乗以上の項を無視して線型化すると、式(7)、(8)、(9)および(10)のように与えられる。 
河床の変位を式(11)のように表わす。ただし、 $k \cdot l$ は $x_{1} \cdot x_{2}$ 方向の無次元波数

$$
k=\frac{2 \pi H}{L}, \quad l=\frac{m \pi H}{B}
$$

$\mathrm{L}$ は波長, $\mathrm{m}$ は横断方向のモード (分割数), $a$ は 無次元複素移動速度、 $\mathrm{t}\left(=\mathrm{tV}_{\mathrm{SO}} / \mathrm{H}\right)$ は無次元時間、 $x=x_{1} / H, y=x_{2} / H, z=x_{3} / H$ は無次元距離、 $\mathrm{V}_{\mathrm{SO}}$ は基本流の表面流速、 $\mathrm{H}$ は平均水深である。

この河床変位に誘起される変動を式(12)のように表 わす。ここに、記号の上にへをはしたものは $\boldsymbol{z}$ のみ の複数関数であり、プライムは $z$ に関する微分を 表わす。

式(12)を式(7)、(8)、(9)、および(10)に代入すると各変 動の振巾の間の関係式は, 式(13)、(14)、(15)および(16)の ように与えられる。ただし、

$$
U=V_{1} / V_{\text {so }}, \quad \varepsilon^{*}=\varepsilon /\left(V_{\text {so }} H\right)
$$

である。これを解けば、式(11)で表わされる河床波上 の流れの三次元的な構造が決定できる。

\section{3. 境界条件}

式(13)、(14)、(15)および(16)を変形すると、式(17)および 式(18)に示す 2 つ微分方程式を得る。これを解いて $\hat{v}^{\prime} \cdot \bar{w}$ が求まれば、式(16)、式(19)より $\widehat{u}^{\prime}, \hat{p}$ がそれぞ れ求まる。式(17)、(18)を解くためには, $\widehat{v}^{\prime} \cdot \widehat{w} に$ 関す る境界条件式が 6 本必要であり, 以下に誘導の概要 を記す。

（1）河床での運動学的条件より

$$
\tilde{v}_{3}=V_{1} \frac{\partial \tilde{\eta}}{\partial x_{1}} \quad \text { at } \quad x_{3}=\tilde{\eta}
$$

式(11)、(12)を代入し、無次元・線型化すると

$$
\widehat{w}(0)=k U(0) \eta_{0}
$$

（2）水面での運動学的条件より

$$
\widetilde{v}_{3}=V_{1} \frac{\partial \tilde{\xi}}{\partial x_{1}} \quad \text { at } \quad x_{3}=H+\tilde{\xi}
$$

$\widehat{w}^{i v}-\frac{i k U}{\varepsilon^{*}} \widehat{w}^{\prime \prime}+\frac{i k U}{\varepsilon^{*}}\left(k^{2}+l^{2}+\frac{U^{\prime \prime}}{U}\right) \widehat{w}=0$

\section{基本流}

$$
\begin{aligned}
& g I_{0}+\varepsilon \frac{d^{2} V_{1}}{d x_{3}^{2}}=0 \\
& g+\frac{d}{d x_{3}}\left(\frac{P}{\rho}\right)=0
\end{aligned}
$$

\section{変動量}

$V_{1} \frac{\partial \tilde{v}_{1}}{\partial x_{1}}+\tilde{v}_{3} \frac{d V_{1}}{d x_{3}}=-\frac{\partial}{\partial x_{1}}\left(\frac{\tilde{p}}{\rho}\right)+\varepsilon \frac{\partial^{2} \tilde{v}_{1}}{\partial x_{3}^{2}}$

$V_{1} \frac{\partial \tilde{v}_{2}}{\partial x_{1}}=-\frac{\partial}{\partial x_{2}}\left(\frac{\tilde{p}}{\rho}\right)+\varepsilon \frac{\partial^{2} \tilde{v}_{2}}{\partial x_{3}^{2}}$

$V_{1} \frac{\partial \tilde{v}_{3}}{\partial x_{1}}=-\frac{\partial}{\partial x_{3}}\left(\frac{\tilde{p}}{\rho}\right)$

$\frac{\partial \tilde{v}_{1}}{\partial x_{1}}+\frac{\partial \tilde{v}_{2}}{\partial x_{2}}+\frac{\partial \tilde{v}_{3}}{\partial x_{3}}=0$

$\tilde{\eta} / H=\eta_{0} \cos (l y) \exp \{i k(x-a t)\}$

$\tilde{v}_{1} / V_{s o}=\widehat{u}^{\prime}(z) \cos (l y) \exp \{i k(x-a t)\}$

$\tilde{v}_{2} / V_{s o}=i \hat{v}^{\prime}(z) \sin (l y) \exp \{i k(x-a t)\}$

$\tilde{v}_{3} / V_{s o}=i \widehat{w}(z) \cos (l y) \exp \{i k(x-a t)\}$

(12)

$\tilde{p} / \rho V_{s o}^{2}=\hat{p}(z) \cos (l y) \exp \{i k(x-a t)\}$

$i k U \hat{u}^{\prime}+i U^{\prime} \widehat{w}=-i k \hat{p}+\varepsilon^{*} \hat{u}^{\prime \prime}$

(13)

$-k U \hat{v}^{\prime}=l \hat{p}+i \varepsilon^{*} \hat{v}^{\prime \prime}$ (14)

$-k U \widehat{w}=-\hat{p}^{\prime}$

$k \hat{u}^{\prime}+l \widehat{v}^{\prime}+\widehat{w}^{\prime}=0$

$\left(\widehat{v}^{\prime}\right)^{\prime \prime}-\frac{i k U}{\varepsilon^{*}}\left(\widehat{v}^{\prime}\right)=\frac{i l}{\varepsilon^{*}} \cdot \frac{k U^{\prime} \widehat{w}-k U \widehat{w}^{\prime}-i \varepsilon^{*} \widehat{w}^{\prime \prime \prime}}{k^{2}+l^{2}}$

$\hat{p}=\frac{1}{k^{2}+l^{2}}\left\{k U^{\prime} \widehat{w}-k U \widehat{w}^{\prime}-i \varepsilon * \widehat{w}^{\prime \prime}\right\}$

ここに、 $\tilde{\xi}=\hat{\xi} \cos (l y) \exp \{i k(x-a t)\}$ は水面変位である。いま、平均水面での変動圧力が水面変位に比 例すると仮定し、式(12)，(19)の関係を代入して整理すると次式を得る。

$$
\widehat{v}^{\prime}(1)+\frac{k^{2} F_{s o}^{2}}{k^{2}+l^{2}}\left\{\widehat{w}^{\prime}(1)+\frac{i \varepsilon^{*}}{k} \widehat{w}^{\prime \prime \prime}(1)\right\}
$$

ただし, $\mathrm{U}(1)=1, \mathrm{U}^{\prime}(1)=0$ の関係を用いている。また $\mathrm{F}_{\mathrm{SO}}{ }^{2}=\mathrm{V}_{\mathrm{SO}}{ }^{2} /(\mathrm{gH})$ である。 
（3）水面での剪断力が 0 であることより

$$
\tau_{31} \simeq \rho \varepsilon\left(\frac{d V_{1}}{d x_{3}}+\frac{\partial \tilde{v}_{1}}{\partial x_{3}}\right)=0 \quad \text { および } \quad \tau_{32} \simeq \rho \varepsilon \frac{\partial \tilde{v}_{2}}{\partial x_{3}}=0 \quad \text { at } \quad x_{3}=H+\tilde{\xi}
$$

上の第 2 式より、第 3 の条件式(25)を得る。

$$
\widehat{v}^{\prime \prime}(1)=0
$$

また、第 1 式に式(16)、式(25)の関係を代入すれば、第 4 の条件式(26)を得る。 $\widehat{w}^{\prime \prime}(1)-U^{\prime \prime}(1) \widehat{w}(1)=0$

（4）河床での剪断力条件より

$$
\tau_{31} \simeq \rho u_{*}^{2} \quad \text { および } \frac{\tau_{32}}{\rho u_{*}^{2}}=\frac{\tilde{v}_{2}}{V_{1}}+\alpha_{3} \frac{\partial \tilde{\eta}}{\partial x_{2}} \quad \text { at } x_{3}=\tilde{\eta}
$$

ここに、u*は局所マサツ速度。第 2 式は斜面上の砂粒運動の解析から求めた関係式である ${ }^{2)}$ 。局所マサツ 速度をこれまでに表われた変動量で表現するため、流れの抵抗則と水深方向の局所平均流速 $v_{m}$ をそれぞれ 次のように表わす。

$$
\frac{v_{m}}{u *}=6.0+2.5 \ln \frac{h}{k_{s}} \cdots \cdots(26) \quad v_{m}=\frac{1}{h} \int_{\tilde{n}}^{H+\tilde{\xi}}\left(V_{1}+\tilde{v}_{1}\right) d x_{3} \cdots \cdots(27)
$$

式(26)、(27)および式(5)を解いて得られる基本流の流速分布式を式(25)に代入して無次元・線型化を行なって整理 すると、次の 2 つ条件式を得る。

$$
\begin{aligned}
\frac{1}{k U^{\prime}(0)}\left\{l \widehat{v}^{\prime \prime}(0)+\widehat{w}^{\prime \prime}(0)\right\} & -\frac{1}{k\left(1-\beta_{*} / 6\right)}\{l[\widehat{v}(1)-\widehat{v}(0)]+\widehat{w}(1)-\widehat{w}(0)\} \\
& +\frac{1}{k}\left(\frac{2.5}{\varphi_{0}}+\frac{\beta_{*} / 6}{1-\beta_{*} / 6}\right) \widehat{w}(1)=\left\{\frac{2.5}{\varphi_{0}}-\frac{\beta_{*} / 2}{1-\beta_{*} / 6}+\frac{U^{\prime \prime}(0)}{U^{\prime}(0)}\right\} \eta_{0} \\
\beta * \widehat{v}^{\prime \prime}(0)-\widehat{v}^{\prime}(0) / U(0)= & i \alpha_{3} l \eta_{0}
\end{aligned}
$$

ここに, $\varphi_{0}=V_{m} / \bar{u}_{*}$ は基本流の抵抗係数, $\beta *=\left(\bar{u}_{*} / V_{s o}\right)^{2} / \varepsilon^{*}$

\section{4. 流れの構造}

式(17)および(18)）を上で求めた境界条件のもとで解く わけであるが、係数には $z$ の関数 Uが含まれており 厳密解を得ることはできない。数値解析的に求めた解 の 1 例を図 -2 に実線で示す。しかし、数値解では後 の解析に不便であり、また計算にかなりの時間を要す るためUを定数と見做して近似解を求めた。 $\varepsilon_{*} \ll$ 1 であることから、式(17)の特性方程式の根の第 1 次近 似值は次のようになる。
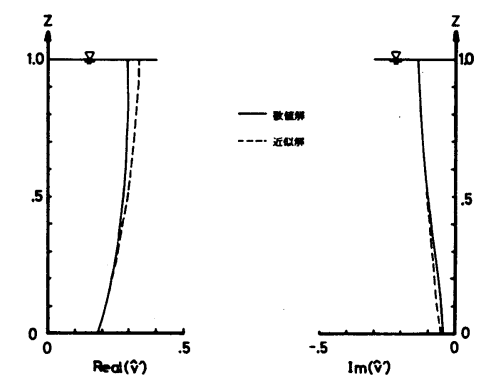

$$
R=\left\{\begin{array}{l} 
\pm R_{1}= \pm \sqrt{\frac{i k U_{0}}{\varepsilon^{*}}} \\
\pm R_{2}= \pm \sqrt{k^{2}+l^{2}+U_{0}^{n} / U_{0}}
\end{array}\right.
$$

したがって

$$
\widehat{w}(z)=c_{1} e^{R_{1} z}+c_{2} e^{-R_{1} z}+c_{3} e^{R_{2} z}+c_{4} e^{-R_{2} z}
$$

また、式(18)の解は定数変化法より容易に求まり、

$$
\begin{aligned}
\widehat{v}^{\prime}(z)= & c_{1} g_{1}(z) e^{R_{1} z}+c_{2} g_{2}(z) e^{-R_{1} z}+c_{3} g_{3}(z) e^{R_{2} z} \\
& +c_{4} g_{4}(z) e^{-R_{2} z}+c_{5} e^{R_{2} z}+c_{6} e^{-R_{2} z}
\end{aligned}
$$
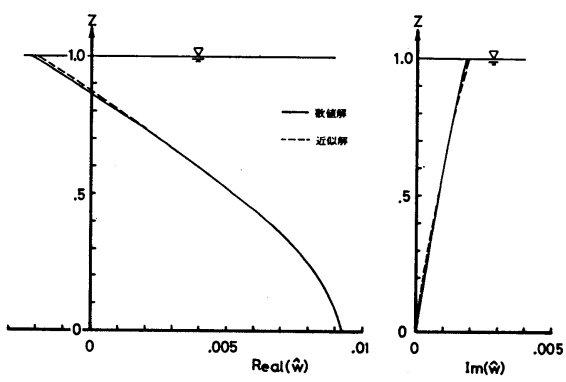

图-2 $\hat{v} \cdot \widehat{w}$ の分布形の 1 例 $(I=0.01, \tau * 0=0.2)$

ただし、 $g_{i}(z)$ は式(18)の右辺の積分より決まる既知関 
数である。境界条件より定数 $\mathrm{c}_{\imath}$ を決めると図一 2 の破線のようになり、近似解は数值解と良く一致している ことが確かめられる。

\section{5. 中規模河床形態上の流砂の運動}

上の解析で、河床波上の流れの 3 次元構造が決定されたので、次に流砂の運動について考察を進める。流 砂は運動形態によって掃流砂と浮遊砂に分けられる。両形式の厳密な区分については議論の余地が多く残さ れているが、ここでは一般的な取り扱いに準じている。

（1）掃流砂の変動掃流砂量はいわゆる掃流砂公式を用いて、掃流力 $\tau_{*}$ の関数として表わされ る。流砂量と掃流力の間に存在する遅れ距離 $\delta$, 河床斜面の流砂量に及ぼす重力効果を導入すると 2$) 、 x \cdot y$ 方向の掃流砂量の変動成分はそれぞれ次式のように与えられる。

$$
\frac{\tilde{q}_{B 1}(x, y)}{q_{B 0}}=\frac{\phi^{\prime}\left(\tau *_{0}\right)}{\phi\left(\tau *_{0}\right)} \tilde{\tau} *(x-\delta, y), \quad \frac{\tilde{q}_{B 2}(x, y)}{q_{B 0}}=\frac{v(x, y, 0)}{U(0)}+\alpha_{4} \frac{\partial \eta}{\partial y}
$$

ここに、 $q_{B 0}=\phi\left(\tau *_{0}\right)$ は平均流砂量, $v=\tilde{v}_{2} / V_{s o}, \eta=\tilde{\eta} / H$ である。

(2) 浮遊砂の変動浮遊砂濃度 $c$ は次の輸送方程式を満足する。 $w_{f}$ は沈降速度。

$$
\frac{\partial c}{\partial t}+v_{j} \frac{\partial c}{\partial x_{j}}=\frac{\partial}{\partial x_{j}}\left(\varepsilon_{j} \frac{\partial c}{\partial x_{j}}\right)+w_{j} \frac{\partial c}{\partial x_{3}}
$$

濃度 $c$ を平均值と変動量に分けて、 $c=\bar{c}\left(x_{3}\right)+\tilde{c}$ と表わし、 $\varepsilon_{j}=\varepsilon(=$ const $)$ および凝似定常の仮定ができる ものとすれば、平均値および変動量に対してそれぞれ次の無次元・線型方程式を得る。

$$
\varepsilon * \frac{\partial \bar{c}}{\partial z^{2}}+w_{f}^{*} \frac{\partial \bar{c}}{\partial z}=0 \quad \cdots \cdots \cdots(35), \quad U \frac{\partial \tilde{c}}{\partial x}+w \frac{d \bar{c}}{d z}=\varepsilon^{*} \nabla^{2} \tilde{c}+w_{f}^{*} \frac{\partial \tilde{c}}{\partial z}
$$

ここに、 $w_{f}^{*}=w_{s} / V_{s o}, w=\tilde{u}_{3} / V_{s o}, \nabla^{2}=\partial^{2} / \partial x^{2}+\partial^{2} / \partial y^{2}+\partial^{2} / \partial z^{2}$ 。式(35)を解けば、いわゆる指数 型の（平均）濃度分布式が得られる。 $\tilde{c}=\hat{c}(z) \cos (l y) \cdot \exp \{i k(x-a t)\}$ 亡表わし式(36)に代入すると

$$
\hat{c}^{\prime \prime}+\frac{w_{f}^{*}}{\varepsilon^{*}} \hat{c}^{\prime}-\left\{k^{2}+l^{2}+\frac{i k U}{\varepsilon^{*}}\right\} \hat{c}=\frac{i \bar{c}^{\prime}}{\varepsilon^{*}} \widehat{w}
$$

となり、上式を適当な境界条件のもとに解けば、濃度変動 $\tilde{c}$ が決定される。

（3）濃度変数の境界条件第 1 の境界条件は水面での sediment flux $=0$ で与えられる。

$$
\hat{c}^{\prime}(1)+\frac{w_{f}^{*}}{\varepsilon^{*}} \widehat{c}(1)=0
$$

第 2 の境界条件は、河床近くの基準点濃度式より与えられる。板倉・岸 ${ }^{3)}$ は基準点として慣用される水深の $5 \%$ の位置での濃度の決定式 $c_{b}=\Gamma(\tau *)$ を提案している。この関係が局所的にも成立するものとすれば

$$
\bar{c}\left(x_{3}\right)+\tilde{c}\left(x_{3}\right)=\Gamma\left(\tau *_{0}+\tilde{\tau} *\right) \quad \text { at } x_{3}=\tilde{\eta}+0.05(H+\tilde{\xi}-\tilde{\eta})
$$

上式を線型化すれば第 2 の境界条件式は次のように与えられる。

$$
\hat{c}(0.05)+\left.\left\{\eta_{0}+0.05\left(\tilde{\xi}-\eta_{0}\right)\right\} \frac{d \bar{c}}{d z}\right|_{0.05}=\left.\frac{d \Gamma}{d \tau_{*}}\right|_{\tau_{* 0}} \cdot \hat{\tau} *
$$

ただし、 $\hat{\tau} *$ は式(26)、(27)の関数より次式のように与えられる。

$$
\hat{\tau} *=\tau *_{0}\left\{\left(\frac{2.5}{\varphi_{0}}+\frac{\beta_{*} / 6}{1-\beta_{*} / 6}\right) \hat{\xi}-\left(\frac{2.5}{\varphi_{0}}-\frac{\beta * / 2}{1-\beta_{*} / 6}\right) \eta_{0}+\frac{1}{1-\beta * / 6}[\hat{u}(1)-\hat{u}(0)]\right\}
$$

(4) 変動濃度の分布形

式(37)を境界条件式(38)、(40)のもとに解く。流れの解析の場合と同様に、 式(37)の右辺には $z$ の関数 $\mathrm{U}(z)$ を含んでいる故、数值解と近似解を求めて比較した。数值解では $\widehat{w}, \hat{u}$ も数 值解で求めたものを、近似解では $\widehat{w} \cdot \widehat{u}$ の近似解をそれぞれ対応して用いている。図一 3 に計算結果の 1 例 を示す。実線が数值解, 破線が近似解である。両者は良く一致している。 


\section{6. 河床安定解析と領域区分}

上の解析で掃流砂量および浮遊砂量の変動が求まったので、 流砂の連続式より河床変位の時間的な変化を論ずることがで きる。流砂の連続式は次式で与えられる。

$$
\begin{aligned}
\frac{\partial \tilde{\eta}}{\partial t} & +\frac{1}{1-n}\left\{\frac{\partial q_{B 1}}{\partial x_{1}}+\frac{\partial q_{B 2}}{\partial x_{2}}\right. \\
& \left.+\frac{\partial}{\partial x_{1}} \int_{\tilde{\eta}}^{H+\tilde{\xi}}\left(v_{1} c\right) d x_{3}+\frac{\partial}{\partial x_{2}} \int_{\tilde{\eta}}^{H+\tilde{\xi}}\left(v_{2} c\right) d x_{3}\right\}=0
\end{aligned}
$$

\section{ここに、 $\mathrm{n}$ は河床砂の空隙率である。}

前節までに求めた関係式を上式に代入して整理すれば、複素 移動速度 $a$ に関する表式を得る、式形は煩雑であるから省略す るが、 $a$ の決定に関与するパラメー夕を整理すれば次のように なる。

$$
a=a\left(\tau_{*_{0}}, I, w_{s} / \bar{u}_{*}, k, l\right)
$$

ここに、I は平均河床勾配である。掃流砂だけの場合と比較す ると, 浮遊砂量と規定するパラメータ $w_{f} / u *$ が加わっている。

良く知られているように、 $a$ の実部 $a_{r}$ は河床変位の伝播方 向を表わし、 $a_{r}>0$ は上流に、 $a_{r}<0$ は下流に移動する。また、 虚部 $a_{i}$ は河床変位の振巾の時間的変化に表わし、 $a_{i}>0$ では 時間とともに増巾し、 $a_{i}<0$ では減衰する。

図ー4に計算結果の 1 例を示す。実線で囲まれた範囲の内側 が $a_{i}>0$ となる領域である。また、一点鎖線の左側、k が 0 に近い部分で $a_{r}>0$ となる他は、ほぼ全域で $a_{r}<0$ となって いる。比較のため、浮遊砂を無視した場合の不安定領域 $\left(a_{i}\right.$ $>0$ ）を計算すると、破線で囲まれた領域となる。浮遊砂が河 床変位の安定・不安定に大きく寄与していることがこの図から 判る。

次に, 中規模河床形態の形成領域区分を上の安定解析の結果 を利用して理論的に求める。領域区分を明らかにするためには、与えられた水理条件・河道条件のもとでど のような波数 $k \cdot l$ の河床波が卓越するか調べることになる。このための重要な手掛りとなる考え方が Engelund・Skovgaardによって示された。彼等は $\mathrm{B} / \mathrm{H}$ の值が与えられたとき、lは離散的な值しかとり得

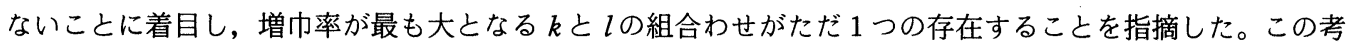
え方に従えば、領域区分は次のパラメータの組合わせで表現できることになる。

$$
\text { 領域区分の区分パラメータ }=\left[\tau *_{0}, I, w_{f} / \bar{u}_{*}, B / H\right]
$$

Engelund らは具体的な計算を行っていないが，その後この考え方を導入して Freds $\phi \mathrm{e}^{4)}$ 、著者ら ${ }^{2)}$ は流れを 2 次元浅水性としたモデルで領域区分線を理論的に求め,その有用性を確かめた。ここでも同様の方法によっ て、領域区分図を求める。具体的手順は参考文献１）２）４）などに詳しいので省略する。 
図ー5・6に計算結果の例を示す。ただし、 両図では $w_{f} / \bar{u} *$ の代りに直接粒径 $\mathrm{d}$ をとっ て示してある。浮遊砂の発生限界掃流力 $\tau *_{c s}$ はdに大きく依存するが、これを強調するた めである。

$\tau *_{0}<\tau *_{c s}$ では、区分線の位置は粒径に 無関係に決まるが、 $\tau *_{0} .>\tau * c s$ では粒径ご とに区分線の位置が異なる。ただし、 $\mathrm{d}>1 \mathrm{~mm}$ では $\tau * c s$ の值に大きな変化はないから、浮 遊砂発生後の区分線の位置も再び粒径に無関 係に決まることになる。

図ー5・6に見られるように、浮遊限界掃 流力以上の掃流力では、単列砂州の形成領域 を与える $\mathrm{B} / \mathrm{H}$ の範囲が拡大していること がわかる。

図-5・6には、著者らの 2 次元浅水流乇 デルで求めた区分線を破線で示してある。こ のモデルでは、掃流砂のみを対象にして解折 した。本解析モデルによる区分線（実線）と 比較すると、 $\tau *_{0}<\tau * c s$ で浮遊砂が存在し ない場合には、両者には大きなちがいが認め られない。

また、眓ー5にはこれまでに行なわれた水 路実験の結果をプロットしてある。これらの 実験值は、掃流砂が卓越する水理条件のも之 で実施されたものである。浮遊砂がない場合

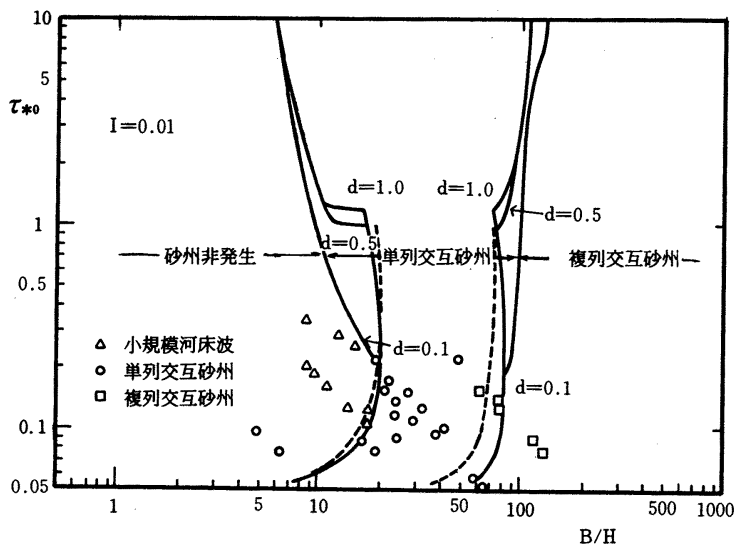

图-5 領域区分図 $(I=0.01$ の例 $)$

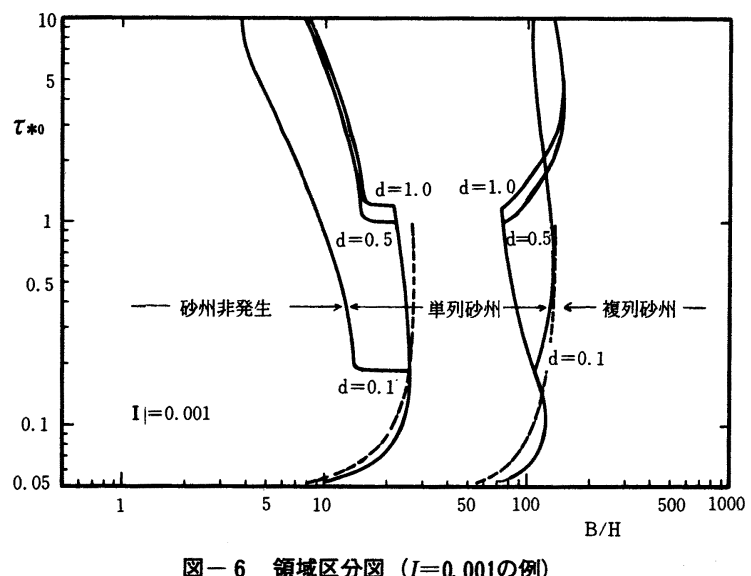

図一 6 領域区分図 $(I=0.001$ の例) の理論区分線は、これらの資料の河床形態のちがいを比較的よく区分していることがわかる。浮遊砂が卓越 する水理条件での水路実験は現在のところ見あたらず、理論解析の妥当性を検証することはできなかった。 今後の課題としたい。

謝辞本研究の一部は文部省科学研究補助金、自然災害特別研究(1)、沖積地河川の河道の治水安全度向 上に関する研究 (研究課題番号 5702003)、代表 岸力、の補助を受けた。また、本研究の計算に当っては 当時本学院生 関沢元治君（現建設省）の熱心な協力を得た。とにも記して謝意を表する。

\section{参考文献}

1) Engelund, Skovgaard : On the origin of meandering and braiding in alluvial streams, J. Fluid Mech. vol. 57, 1973

2 ) 黒木幹男・岸力：沖積河道の流路形態の領域区分に関する研究、第26回水理講演会論文集、1982

3 ) 板倉忠興 - 岸力: Open channel flow with suspended sediments, Proc. ASCE Jour. HY- 8, 1980

4 ) Freds $\phi$ e : Meandering and braiding of rivers, J. Fluid Mech. vol. 84 part 4, 1978 